\title{
Combined surgical and ablative cure for localized sternal compression-induced cardiomyopathy and ventricular tachyarrhythmia
}

Christopher V. DeSimone, MD, PhD, ${ }^{a}$ Sandeep Sagar, MD, ${ }^{\mathrm{b}}$ Chris Moir, MD, ${ }^{\mathrm{c}}$ and Samuel J. Asirvatham, MD, ${ }^{\mathrm{b}, \mathrm{d}}$ Rochester, Minn

From the Departments of Internal Medicine, ${ }^{\mathrm{a}}$ Cardiology, ${ }^{\mathrm{b}}$ Pediatric Surgery, ${ }^{\mathrm{c}}$ and the Division of Pediatric Cardiology, ${ }^{\mathrm{d}}$ Mayo Clinic, Rochester, Minn.

Disclosures: Authors have nothing to disclose with regard to commercial support.

Received for publication Feb 17, 2012; accepted for publication March 16, 2012; available ahead of print April 16, 2012.

Address for reprints: Samuel J. Asirvatham, MD, Divisions of Cardiovascular Diseases and Internal Medicine and Pediatric Cardiology, Department of Pediatric and Adolescent Medicine, Mayo Clinic College of Medicine, 200 First St SW,

Rochester, MN 55905 (E-mail: asirvatham.samuel@mayo.edu).

J Thorac Cardiovasc Surg 2012;144:e85-7

0022-5223/\$0.00

Published by Elsevier Inc. on behalf of The American Association for Thoracic Surgery http://dx.doi.org/10.1016/j.jtcvs.2012.03.033
Ventricular tachyarrhythmia (VT) in structurally normal hearts often arises in the right ventricular outflow $\operatorname{tract}^{1}$ and is characterized by left bundle-branch block (LBBB) inferior axis morphology. ${ }^{2}$ VT of other LBBB morphology has been associated with arrhythmogenic right ventricular cardiomyopathy and moderator bandrelated $\mathrm{VT}^{3}$

We present a case of VT of superior axis LBBB morphology arising from the site of sternal compression on the right ventricular free wall in a patient with pectus excavatum.
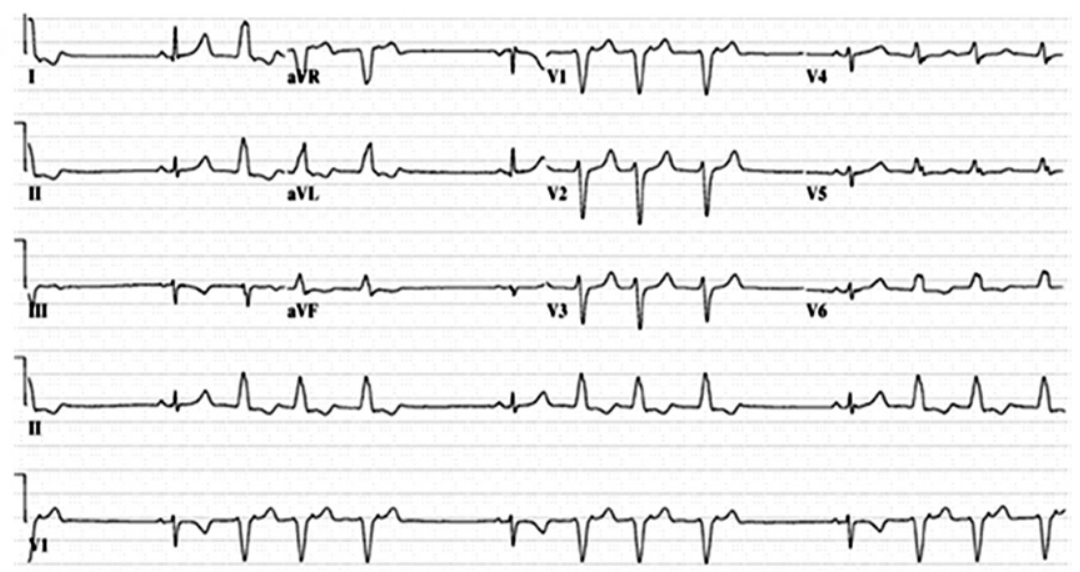

A
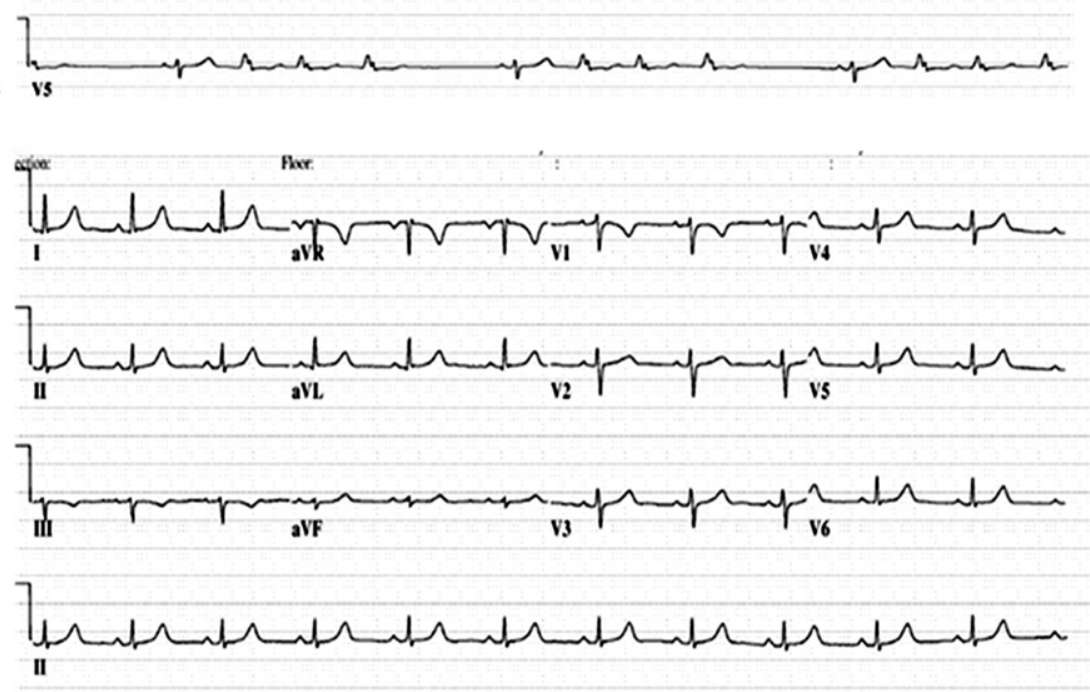

B

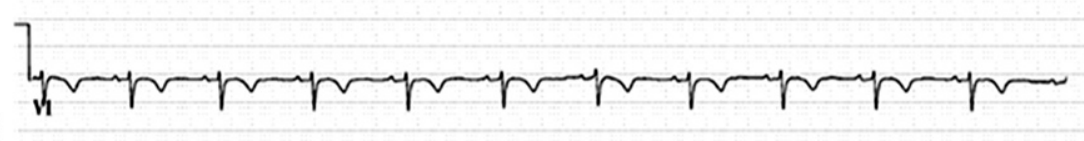

FIGURE 1. A, Preprocedure electrocardiogram showing monomorphic nonsustained ventricular tachyarrhythmia with superior axis left bundle branch block morphology. B, Postprocedure electrocardiogram showing sinus rhythm and no ventricular arrhythmia. 

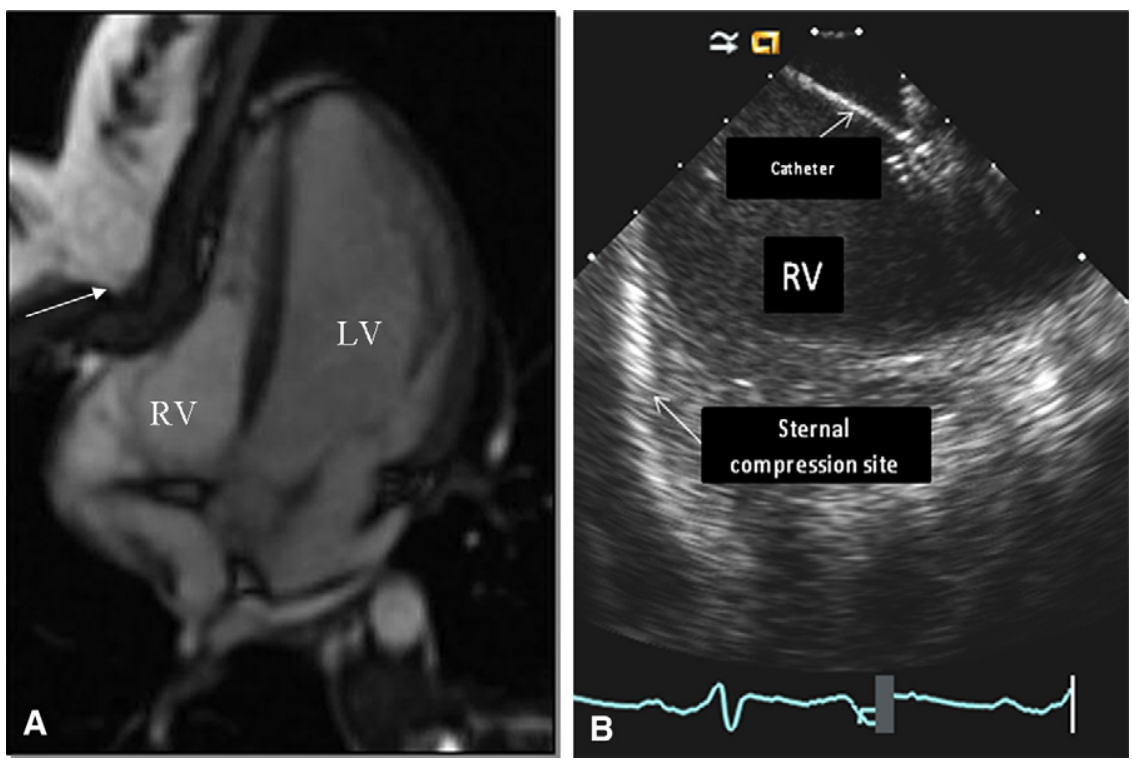

FIGURE 2. A, Cardiac magnetic resonance image showing significant free wall impingement (arrow) as a result of the sternal abnormality. There is severe compression noted on the anterolateral right ventricular $(R V)$ inflow portion. B, Intracardiac ultrasonography showing catheter position during ablation exactly at the location of sternal compression. $L V$, Left ventricle.

The curative invasive electrophysiologic and surgical management is described.

\section{CLINICAL SUMMARY}

A 16-year-old otherwise healthy girl was seen with rapid tachypalpitation. On physical examination, ectopic beats and pectus excavatum were found to be present. Her preablation electrocardiogram (Figure 1) showed monomorphic nonsustained VT with LBBB superior axis morphology.
There was no evidence of arrhythmogenic right ventricular cardiomyopathy. ${ }^{2}$ Cardiac magnetic resonance imaging demonstrated sternal impingement on the anterolateral right ventricular free wall (Figure 2, $A$ ).

A transthoracic echocardiogram appeared normal, and 24hour Holter monitoring recorded multiple runs of sustained and nonsustained VT and premature ventricular contractions. Electrophysiologic study was performed to assess the arrhythmogenic substrate and possibly ablate the symptomatic VT.
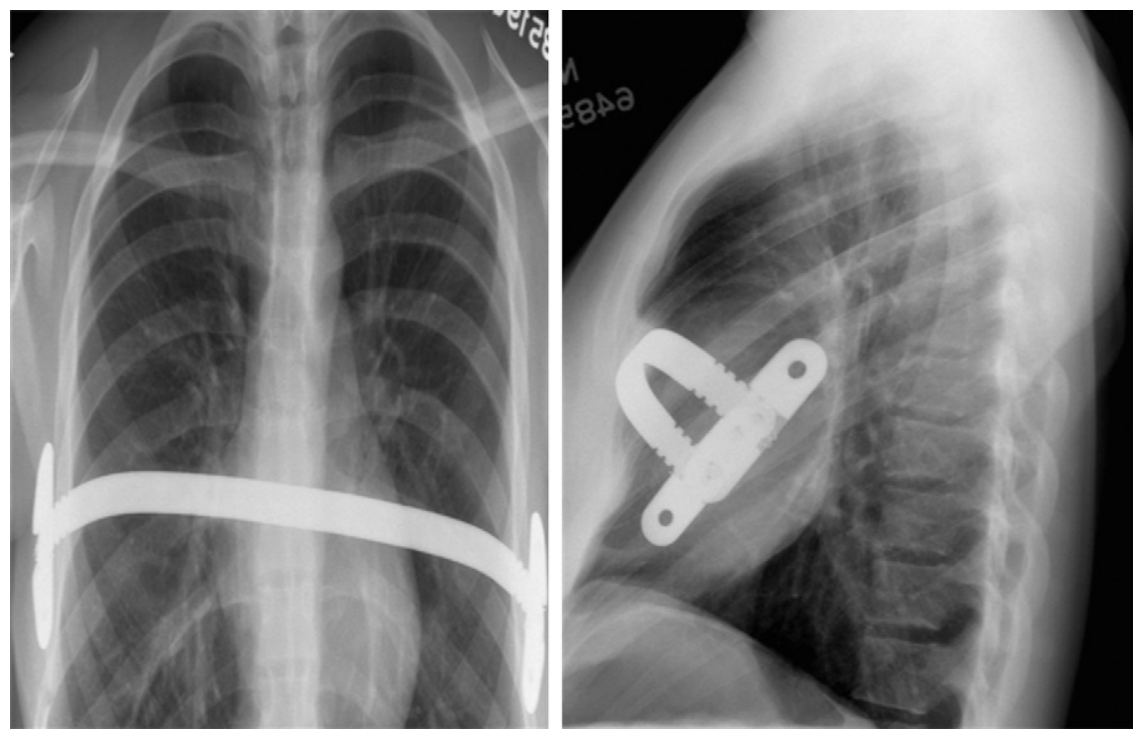

FIGURE 3. Anteroposterior and lateral chest radiographs taken after sternal bar correction of pectus excavatum deformity. The Nuss bar is seen across the patient's chest and underneath the sternum. This shows that the bar is preventing sternal compression of the right ventricle. 


\section{Electrophysiologic Study and Ablation}

With the patient under conscious sedation, endovascular catheters were placed in the standard fashion. Intracardiac ultrasonography with a linear phased-array imaging probe (Acuson; Siemens Medical Solutions USA, Mountain View, Calif) was used for detailed imaging of the right ventricle and to aid catheter manipulation. Sustained VT was induced with ventricular extra stimulation and matched the clinical VT and predominate premature ventricular contraction morphology. Three-dimensional electroanatomic mapping with ultrasonographic guidance and image integration with the magnetic resonance imaging was performed (Carto; Biosense Webster, Inc, Diamond Bar, Calif). The site of earliest activation during VT and where a perfect pace map was obtained was directly opposite the site of sternal compression identified with real-time intracardiac ultrasonography (Figure 2, B). Ablation at this site terminated VT, which was no longer inducible after that.

\section{Further Clinical and Surgical Course}

Because of continued right ventricular compression and the possibility of ongoing arrhythmogenesis, we proceeded with surgical pectus correction. With a lateral incision, a 5-mm cannula was inserted for visualization of the deepest part of the pectus. A bar was positioned across the mediastinum, and the sternum was serially elevated 10 times as counterpressure was applied to the distal sternum and costal margin, and a 12-inch prefashioned Nuss strut was pulled through successfully. Cardiac impingement was successfully relieved (Figure 3).

Because VT was noninducible, a cardiac defibrillator was not implanted. A repeated electrophysiologic study was done 1 year later, with normal results. The patient has had no recurrence of VT 2 years after the procedure.

\section{DISCUSSION}

We present here a case of focal electrocardiomyopathy that resulted from sternal compression and gave rise to VT. A combined electrophysiologic and ablative approach with surgical decompression was curative. When patients have unusual electrocardiographically based morphology for right ventricular VT not consistent with right ventricular outflow tract origin, ${ }^{4}$ less common causes of VT, including compression cardiomyopathy, should be considered.

\section{References}

1. O'Donnell D, Cox D, Bourke J, Mitchell L, Furniss S. Clinical and electrophysiological differences between patients with arrhythmogenic right ventricular dysplasia and right ventricular outflow tract tachycardia. Eur Heart J. 2003;24: 801-10.

2. Marcus F, Zareba W. The electrocardiogram in right ventricular cardiomyopathy/ dysplasia. How can the electrocardiogram assist in understanding the pathologic and functional changes of the heart in this disease? J Electrocardiol. 2009;42: 136.e131-5.

3. Abouezzeddine O, Suleiman M, Buescher T, Kapa S, Friedman PA, Jahangir A, et al. Relevance of endocavitary structures in ablation procedures for ventricular tachycardia. J Cardiovasc Electrophysiol. 2010;21:245-54.

4. Asirvatham SJ. Correlative anatomy for the invasive electrophysiologist: outflow tract and supravalvar arrhythmia. J Cardiovasc Electrophysiol. 2009;20: 955-68.

\title{
Left main coronary artery atresia with tetralogy of Fallot: A novel association
}

\author{
Nikhil Prakash Patil, MS, MRCS, ${ }^{a}$ Smita Mishra, MD, DNB,${ }^{\mathrm{b}}$ Saket Agarwal, MCh, ${ }^{\mathrm{a}}$ and

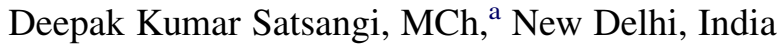

Video clip is available online.

\footnotetext{
From the Department of CTVS, ${ }^{\text {a }}$ G. B. Pant Hospital, New Delhi, India; and the Department of Cardiology, ${ }^{\mathrm{b}}$ Fortis Escorts Heart Institute, New Delhi, India. Disclosures: Authors have nothing to disclose with regard to commercial support. Received for publication Jan 28, 2012; revisions received Feb 24, 2012; accepted for publication March 16, 2012; available ahead of print April 16, 2012.

Address for reprints: Nikhil Prakash Patil, MS, MRCS, Department of CTVS, G. B. Pant Hospital, New Delhi 110002, India (E-mail: drnikhilp@gmail.com).

J Thorac Cardiovasc Surg 2012;144:e87-9

$0022-5223 / \$ 36.00$

Copyright (c) 2012 by The American Association for Thoracic Surgery

http://dx.doi.org/10.1016/j.jtcvs.2012.03.037
}

Left main coronary artery (LMCA) atresia is a rare coronary anomaly in which there is no left coronary ostium, the proximal left main trunk ends blindly, and blood flows from the right coronary artery (RCA) to the left through collaterals and retrogradely in at least 1 of the left-sided arteries. ${ }^{1} \mathrm{~A}$ novel case of LMCA atresia associated with tetralogy of Fallot (TOF) is reported here. The patient underwent successful surgical angioplasty for LMCA reconstruction with concomitant TOF palliation in the setting of biventricular dysfunction.

\section{CLINICAL SUMMARY}

A 2-year-old girl known to have TOF was referred with recurrent cyanotic spells and failure to thrive. Preoperative 